\title{
Editorial: Adeus ao Qualis, a nova fase e a peste!"
}

\begin{abstract}
"Quando a esquerda não rasga horizontes, nem infunde esperanças, a direita ocupa o espaço e draga as perspectivas: é então que a barbárie se transforma em tragédia cotidiana."
\end{abstract}

J. Chasin

\section{Adeus, Qualis!}

Tendo sido gestada em 2004, de forma despretensiosa, por um grupo de professores unidos por experiências editoriais e atuação prática anteriores, a Verinotio esteve nos primeiros anos limitada em termos de divulgação, de diversidade e eventualmente de qualidade ou originalidade dos textos que recebia e publicava, tracejando um percurso modesto e tenteando forjar sua identidade no ecossistema das revistas acadêmicas on-line, cada vez mais superpovoado. Nesse processo, tendo reforçado seu corpo editorial, a revista encontrou sua identidade e optou por enveredar, cada vez mais decididamente, pelo caminho estreito e pedregoso de uma linha editorial muito bem definida e de uma linha de corte baseada na qualidade dos materiais trazidos a lume em suas páginas. Durante todo este percurso e até a atualidade, a revista nunca contou com nenhum suporte financeiro, sendo mantida por um pequeno grupo que também ofertava seu tempo em forma de serviços diversos.

Até 2016, a Verinotio fazia parte de um projeto mais amplo, concebido inicialmente como um espaço de interlocução em ciências humanas, em que atividades de vários tipos eram vinculadas à página inicial do site, incluindo a própria revista. Constatada a impossibilidade de mantê-lo da forma como foi estruturado inicialmente, o comitê editorial decidiu aderir ao software livre denominado Open Journal Systems (OJS), alterando drasticamente o perfil anterior da página. Daí para a frente, a publicação da revista passou a ser o único objetivo da manutenção do site. Esta decisão proporcionou maior agilidade no contato dos editores com autores e revisores, além de permitir a realização do próprio processo de editoração pelo interior mesmo

\footnotetext{
*Agradeço a Vânia Noeli Ferreira de Assunção pelas valiosas sugestões.
} 
do sistema, malgrado alguns inconvenientes, cuja devida solução, aparentemente, ainda não foi totalmente identificada por aqueles que contribuem para 0 aperfeiçoamento técnico da ferramenta.

Dois anos depois, deparamo-nos com um novo desafio. Tratando-se de uma revista independente, sem vínculos com cursos de pós-graduação, ${ }^{1}$ organizações político-partidárias e quejandos, dependemos da submissão de artigos que apresentem sintonia com a nossa linha editorial, já plenamente madura e de caráter marcadamente contracorrente, o que pode gerar e, com certeza, gerou aqui e acolá desgastes e atritos com as tendências predominantes no mundo acadêmico-cultural as quais, no mais das vezes, rejeitam a validade teórica de pesquisar autores e temas que os editores da revista consideramos essenciais. Em outras palavras, embora aderir ao OJS tenha facilitado as atividades editoriais da Verinotio, isso não significou que a revista tenha granjeado o reconhecimento a que ela faz jus, em especial, no meio universitário, que, pelo menos em princípio, seria o ambiente propício para a pesquisa e o debate de alto nível. ${ }^{2}$

É claro que há vários fatores que explicam a situação resumidamente descrita acima. Parece que tudo tem que ver com os efeitos nefastos do "produtivismo acadêmico", que compele os pesquisadores (e também os candidatos a postos desta ordem) a publicar com intensidade os resultados de suas investigações em revistas

\footnotetext{
${ }^{1}$ É verdade que há vínculos com o curso de serviço social da UFF (campus Rio das Ostras) e com o Grupo de Pesquisa Marxologia - Filosofia e estudos confluentes, registrado no diretório de grupos de pesquisa do CNPq, no entanto, cumpre ressaltar que tal condição não propicia hospedagem gratuita no site ou suporte técnico da UFF, nem acesso a verbas específicas e outras facilidades que, normalmente, o vínculo com um curso de pós-graduação, em tese, permitiria.

2 É sobejamente conhecido o fato de que alguns setores do meio acadêmico são bastante refratários aos estudos no campo do marxismo. Barreiras insuperáveis são erguidas, por exemplo, na oferta de disciplinas, na admissão de mestrandos ou doutorandos com projetos desse teor, na obtenção de bolsas de pesquisa, na publicação de artigos, na organização de eventos e assim por diante. A esse respeito, vale lembrar que, diante de acusações perpetradas por um ex-ministro da educação do atual governo, a diretoria da Associação Nacional de Pós-Graduação em Filosofia (Anpof) veio pressurosamente a público se defender, demonstrando, por meio de números, a quase total inexistência de estudos sobre Marx na área. O que, sem dúvida, é verdade, mas é digno de nota que o presidente da entidade à época, em suposta defesa da área diante dos impropérios proferidos pelo então ministro, não tenha lamentado tal fato, ao contrário, tenha desejado manifestar tão somente o desinteresse claro por pesquisas sobre o tema, apressando-se em demonstrar o imenso vazio existente na área. Trata-se, ao fim e ao cabo, de revelação crua da dimensão discricionária que a área de filosofia ostenta no meio acadêmico em relação a tudo que diga respeito a Marx e ao marxismo. Ver a respeito: <http://www.anpof.org/portal/index.php/pt-BR/artigos-em-destaque/2132-levantamento-feito-pelaanpof-indica-baixa-presenca-de-ensino-de-marx-nas-pos-graduacoes-em-filosofia-no-brasil>. À época, - jornal Folha de S. Paulo chegou a publicar matéria sobre 0 assunto: <https://www1.folha.uol.com.br/cotidiano/2019/05/marx-esta-presente-em-apenas-4-de-disciplinasde-pesquisa-em-filosofia.shtml>.
} 
bem classificadas no Qualis. ${ }^{3}$ E, infelizmente, no quadriênio 2013-16, ou seja, na última classificação oficialmente divulgada, ${ }^{4}$ a posição da Verinotio não é das melhores. É evidente que esse "mau desempenho", estabelecido sabe-se lá por quais critérios, inibe ou mesmo afasta os autores, ainda que, inicialmente, o comitê editorial não tenha atentado para tal fato. A reformulação da revista com vistas a atender a certos requisitos do Qualis - não todos! - se deu apenas em 2018.

Por que a demora em ajustar o perfil da Verinotio aos critérios que permitiriam - em tese! - uma melhor classificação e o consequente interesse de autores em submeter seus trabalhos à revista? A resposta a tal indagação se encontra estampada na nossa página inicial. Se não, vejamos:

O propósito de Verinotio é difundir produções teóricas e estabelecer
intercâmbio entre grupos de pesquisas e investigadores individuais que
atuem no campo do marxismo, do humanismo e de concepções filosóficas
afins e que desenvolvam reflexões críticas tendo por objeto o
desenvolvimento histórico-social das formas de interatividade e de suas
expressões ideais (ciência, moral, arte etc.).
Nesse sentido, a linha editorial de Verinotio tem por orientação e parâmetro
principais a compreensão conceitual qualificada e lúcida das raízes concretas
dos desafios e dilemas da sociabilidade atual, visando à reposição do
reconhecimento teórico das determinações categoriais que se articulam e
perfazem a vida social moderna e contemporânea. Desse perfilado teorético
fazem parte, além da obra de Marx, as formulações filosóficas e científicas
que, em convergência ou paralelismo com esta, tiveram e têm por télos a
apreensão racional do mundo humano e o enfrentamento das contendas
ideológicas em torno dos problemas sociais. Trata-se, pois, de um resgate
do humano, de um humanismo crítico no qual se apreenda conceitualmente
o complexo de elementos e relações que constituem a vida societária.
Totalidade de teor, em certa medida, contraditório, que enlaça o
desdobramento das possibilidades humanas, virtualmente infinitas, de
objetivação e de cultura com uma imensidade de mazelas e aporias. Não se
tratando, portanto, de um elogio abstrato a uma suposta essencialidade
humana, mas de escrutínio cuidadoso e rigoroso dos óbices atuais e das
perspectivas de futuro.

Evidentemente, tais diretivas de cunho editorial não surgiram há apenas 17 anos, com a publicação do primeiro número da revista, mas remontam, pelo menos, aos primeiros anos da década de 1980, com a criação do projeto Ensaio, ressalvando-se,

\footnotetext{
${ }^{3}$ De acordo com Barradas Barata (2016), o Qualis Periódicos é uma ferramenta criada somente para possibilitar a avaliação dos programas de pós-graduação no Brasil. No entanto, apesar da insistência do referido autor e de órgãos oficiais no sentido oposto, o fato é que acabou se tornando instrumento para avaliar não somente o desempenho individual do pesquisador, como também a qualidade dos periódicos científicos, tendo sido utilizado largamente em concursos públicos, distribuição de bolsas, credenciamento e recredenciamento de docentes pelos programas de pós-graduação e outras finalidades. Ou seja, tem servido amplamente para propósitos distintos daquele para o qual foi concebido orginalmente.

${ }^{4} \mathrm{Cf}$.

$<$ https://sucupira.capes.gov.br/sucupira/public/consultas/coleta/veiculoPublicacaoQualis/listaConsulta GeralPeriodicos.jsf>, acesso em 9 jul. 2021.
} 
é claro, não se tratar de propostas de mesma envergadura e amplitude. Acerca daquela quadra histórica, de acordo com a rememoração de Chasin,

o panorama nacional exibia a reconversão da ditadura militar em distensão democrática, ao lado do refluxo aflitivo da movimentação social dos trabalhadores, abatida na sequência imediata à sua vigorosa reemergência nos dois últimos anos da década anterior - lampejo marcante, mas episódico, que não teve alento para engendrar sua autossustentação e foi minado pela sua imediata instrumentalização político-partidária (CHASIN, 1999, p. 1).

Surgida num momento marcante da cena histórica brasileira, a Revista Ensaio e, posteriormente, a própria editora que levou seu nome, procurou, desde seus inícios, incentivar a criação de um movimento de ideias de modo a contribuir para a identificação dos rumos possíveis a serem seguidos no conturbado cenário de então. Ainda que tal projeto tenha sido abalroado por motivos de várias ordens, sua linha diretiva básica permanece acertada e, mais do que nunca, necessária.

Convém, por essa razão, relembrar alguns traços marcantes daquele projeto, tomando novamente as palavras de Chasin a respeito. Diz ele:

\begin{abstract}
Afrontando mitos e preconceitos da prática vulgar que engolfou o século, emergiu então, não sem alguns enganos e tropeços iniciais, a evidência da prioridade radical, na ordem das necessidades intrínsecas ao campo da esquerda, de um Movimento de Ideias, voltado à produção e difusão teóricas e direcionado à redescoberta da obra de Marx, bem como à tematização da problemática brasileira. Projeto ambicioso por seus alvos, foi desde logo equilibrado pela prudência e comedimento de sua prática intelectual, pretendendo antes rigor no próprio trabalho do que lutar por reconhecimento, indiferente em especial aos aplausos fáceis, complacentemente permutados (CHASIN, 1999, p. 1).
\end{abstract}

Ora, transcorridos cerca de 40 anos, é forçoso reconhecer que, a despeito dos entraves e dificuldades de todas as ordens que enfrentou, as linhas mestras daquela proposta continuam válidas, embora necessitem ser redimensionadas tendo em vista as disposições e o contexto atual, ainda mais problemático e grave do que o cenário daqueles anos.

A validade, até os dias que se seguem, das linhas diretivas do movimento Ensaio foi confirmada, sobretudo nas pesquisas desenvolvidas nos últimos 20 anos por vários professores e pesquisadores em geral que se aproximaram da proposta da Verinotio, notadamente no que diz respeito à elucidação das dimensões fundamentais do legado marxiano, pouco conhecidas ou malbaratadas pelos intérpretes que dominaram o século XX e que, infelizmente, continuam a proliferar, ainda que em menor monta.

As sucessivas edições da Verinotio comprovam essa assertiva, tendo em vista os diversos artigos publicados que tratam de maneira rigorosa desses problemas. 
Ademais, pode-se também indicar, nesse mesmo sentido, as pesquisas sobre a obra de Lukács e outros autores marxistas relevantes, como é o caso de Antonio Gramsci, por exemplo. Dignos de nota também são os trabalhos voltados à realidade brasileira, com ênfase especial àqueles que tiveram por tema o pensamento conservador. Não se poderia desconsiderar, do mesmo modo, nesse rápido recordatório, o caráter da maior parte dos editoriais recentemente veiculados pela revista, nos quais a equipe editorial não apenas teceu considerações a respeito do conteúdo da respectiva edição, apresentando os traços marcantes de cada uma das contribuições publicadas, mas também procurou avaliar criticamente temas atinentes à recepção de Marx e aos desafios do momento presente. Pelo seu teor, a rememoração desses editoriais se justifica inclusive por seus eventuais equívocos. Dirão, talvez muitos, que especial ou exclusivamente por isso. Mesmo assim, eles ilustram uma tentativa de manter entreabertas as janelas e as portas da revolução social, motivo pelo qual são, de certo modo, superiores, creio eu, a escritos tidos como muito melhores, veiculados por outros periódicos, que não tiveram tal preocupação.

Como é facilmente perceptível, a linha editorial da Verinotio destoa da das revistas de perfil eminentemente acadêmico, muito embora preze a pesquisa rigorosa, atenta e de alto nível. Ao mesmo tempo, distancia-se vigorosamente de algumas publicações de caráter eminentemente político, voltadas que estão para a difusão de teses formuladas no interior de agrupamentos político-partidários ditos de esquerda, engrenagens de longa e pérfida história que esterilizam, reprimem e mutilam iniciativas distintas da "linha oficial". Ou seja, o perfil editorial da Verinotio não se identifica com - padrão supostamente neutro e desinteressado de periódicos eminentemente acadêmicos, mas também não se confunde - e não quer se confundir - com publicações voltadas à "agitação e propaganda", dentro dos moldes convencionais das agremiações políticas. Pretende, diferentemente do que ocorre nos "guetos ideológicos", resgatar a proposta de um movimento de ideias que venha a contribuir para o desvelamento dos desafios que o tempo presente nos coloca, como os termos explícitos da linha editorial acima referida tão bem manifestam.

Evidentemente, abraçando uma linha editorial desse talhe, a Verinotio não encontra guarida em rankings do tipo Qualis, o que por si só já era esperado, na exata medida em que, de modo geral, com exceção de alguns poucos nichos, os "pares", isto é, aqueles que realizam a avaliação da produção dos cursos de pós-graduação, não são muito simpáticos em relação a pesquisas em torno da obra de Marx. 
A revista, no entanto, não tem por meta a obtenção de reconhecimento dos órgãos oficiais governamentais, quaisquer que sejam e, ademais, está impedida, por sua própria linha editorial, de atender aos requisitos reverenciados pelo Qualis/Capes, tidos como os únicos capazes de promover publicações de qualidade. Ou seja, para atender a tais requisitos, a revista teria de renunciar a suas linhas diretivas. E este definitivamente - não é o caso.

É bem verdade que a prática do ranqueamento não é um fenômeno recente, e muito menos restrito ao país. Tudo indica que, mais de uma vez, pesquisadores brasileiros pressionaram pela adoção de critérios de classificação com o objetivo de "integrar-se aos padrões estadunidenses", o que "implicava a busca por algum mecanismo de medição comparativa que, ao menos, iniciasse um processo de aproximação com os países de língua inglesa e suas empresas certificatórias" (GABARDO; HACHEM; HAMADA, 2018, p. 147). Adotado e difundido em várias áreas, mas nascido sobretudo para avaliar desempenho no trabalho (o assim chamado "ranqueamento de performance"), talvez por isso mesmo, tem sido utilizado, por parte das empresas, como instrumento para obtenção, por exemplo, de boa visibilidade no Google, só para se ter uma ideia rápida da disseminação de seu uso, o que parece ser bastante coerente num mundo em que o número de likes pode determinar o destino de uma vida. É bem conhecida também a hierarquização das universidades. Portanto, - fenômeno do ranqueamento não demorou a chegar às avaliações de cursos, professores e discentes.

A despeito de sua larga disseminação, ou por isso mesmo, tal procedimento já vem sendo questionado amplamente, sobretudo no ambiente universitário e em instituições de pesquisa prestigiadas. Um dos critérios Qualis considerado o mais importante, nomeadamente, o fator de impacto, vem sendo contestado mundo afora. De fato, como divulgado recentemente,

\begin{abstract}
a Universidade de Utrecht, na Holanda, está formalmente abandonando o fator de impacto como critério tanto para a contratação como para a promoção de docentes. Critérios exclusivamente numéricos focados, por exemplo, no fator-H ou na publicação de artigos em revistas de alto impacto serão substituídos em favor de critérios qualitativos como aç̃̃es para a promoção da ciência aberta e o trabalho em grupo (YAMASHITA, 2021).
\end{abstract}

É bem verdade que adoção do Qualis gerou desconforto entre os pesquisadores desde o início de sua implantação (cf. MARQUES, 2021). Tido pelos técnicos da Capes e por alguns representantes de comissão de área como única alternativa possível para "mensurar" a qualidade dos periódicos no país, está longe de ser algo consensual - e 
as dificuldades encontradas, derivadas, em parte, da administração atual da Capes, parecem explicar o atraso na divulgação de nova listagem, a partir da última avaliação quadrienal.

De todo modo, independentemente da publicização dos resultados da última avaliação, o Conselho Editorial da Verinotio decidiu dar "adeus ao Qualis". Em termos práticos, isto significa a adoção de dois critérios fundamentais para a seleção de artigos: de um lado, a qualidade e relevância do trabalho apresentado e, de outro, a sua compatibilidade e a sua convergência com a linha editorial da revista. Evidentemente, a aplicação de tais critérios ficará a cargo da Comissão e do Conselho Editorial da revista, recentemente ampliado, como sói acontecer. Aparentemente óbvia, tal conclusão emergiu a partir da prática levada a cabo nos últimos três anos, em que, como já foi referido, ficou evidenciado o risco de o periódico perder sua identidade, caso $\circ$ atendimento aos requisitos do Qualis passasse a predominar nas decisões editoriais. Em suma, manter a linha editorial e seguir o padrão Qualis são objetivos irreconciliáveis.

\section{Dixit et salvavi anima mean (Karl Marx, Crítica ao Programa de Gotha)}

\section{Nova fase}

Dito o solene adeus ao Qualis, é chegada a hora de inaugurar uma nova fase da Verinotio. De fato, não se trata apenas de uma "renovada" no visual da publicação ou do site, ou mesmo da mudança na diagramação do "miolo" e adoção de novos tipos de fontes na capa (ainda que mudanças dessa natureza sejam positivas), e sim de um certo número de alterações pensadas não apenas para valorizar a história da revista, que completa 17 anos, mas, sobretudo, mirar o futuro (se futuro houver...).

A adoção do subtítulo NOVA FASE tem como pretensão, de um lado, encerrar um ciclo extremamente produtivo de publicações, em que não faltaram artigos, traduções, resenhas e entrevistas de alto valor e que se constituíram na "marca registrada" da revista em sua fase madura, tanto por sua qualidade quanto pela contribuição inestimável para a devida compreensão das polêmicas em torno da obra de Marx e de seu legado, seus desdobramentos teóricos e práticos.

De outra parte, como a própria expressão indica, a nova fase reflete a necessidade de ampliar e diversificar o leque de publicações, sem que a revista propriamente dita perca seu lugar de carro-chefe dos esforços a serem despendidos 
daqui para frente. Em suma, a nova fase é fruto de um momento particular em que os editores, a partir da experiência acumulada e do enfrentamento de vários desafios, buscam novos modos de publicizar os resultados das pesquisas realizadas pelos integrantes do Grupo de Pesquisa Marxologia - Filosofia e estudos confluentes, fundado por J. Chasin, e que completa 25 anos de existência ininterrupta. Evidentemente, não se trata de restringir ou limitar a publicação de contribuições produzidas para além dos limites do grupo de pesquisa, muito pelo contrário! O que se pretende com tal demarcação é deixar claro que, ao darmos adeus ao Qualis, objetivamos, de modo explícito, difundir escritos que tenham

por orientação e parâmetro principais a compreensão conceitual qualificada
e lúcida das raízes concretas dos desafios e dilemas da sociabilidade atual,
visando à reposição do reconhecimento teórico das determinações
categoriais que se articulam e perfazem a vida social moderna e
contemporânea. Desse perfilado teorético fazem parte, além da obra de Marx,
as formulações filosóficas e científicas que, em convergência ou paralelismo
com esta, tiveram e têm por télos a apreensão racional do mundo humano e
o enfrentamento das contendas ideológicas em torno dos problemas sociais, como estampado nas informações sobre a linha editorial da revista.

Que fique bem claro, não temos em mira limitar ou circunscrever submissões, mas fortalecer um movimento cujo norte é priorizar a linha editorial da revista.

\section{A peste}

Estamos, gostemos ou não, queiramos ou não, ainda inseridos na pesada atmosfera deixada pelo fracasso das transições para o socialismo intentadas, e pelas posturas práticas e teóricas nascidas com o stalinismo, que, embora sobrevivam em alguns valhacoutos de reduzida importância efetiva, demonstraram total esgotamento, mas, infelizmente, estão aí a atrapalhar - como estrelas mortas há milênios, cuja luz ainda nos ofusca.

Desde há muito tempo procuramos nos colocar entre dois polos, quais sejam, o mito negativo e a mistificação desarvorada: entre a desconsideração teórica da revolução (emancipação humana) e a prática aviltada que se faz em nome da própria revolução. Se acerca dessa polarização muitos não conseguimos convencer, debite-se esta tremenda falha, em parte, ao padrão intelectivo dominante em nossos tempos, padrão este que impossibilita o diálogo e obscurece a visão dos melhores e mesmo dos bem-intencionados. Agarrar-se aos mitos e mistificações - tanto de um tipo quanto de outro - parece ser o denominador comum das mais variadas polarizações a que se tem assistido, mas, em especial, daquela a que nos referimos aqui. A tarefa é 
urgente e, ao mesmo tempo, monumental: não se trata mais de avaliar "erros" da esquerda, nem mesmo os seus eventuais descaminhos, mas de reconhecer seu colapso. A tragédia se manifesta em todos os escaninhos possíveis, e o mais grave a constatar é que são poucos os esforços em reconhecê-la na sua real envergadura. Não é fácil, sem dúvida. Mais confortável e cômodo é permanecermos atados aos velhos mitos e às carcomidas mistificações. A falta de inteligência da pseudoesquerda atual é seu ponto culminante, isto é, o ponto mais raso do entendimento político, ao qual corresponde, sob várias formas e níveis, o marxismo vulgar, o oportunismo intelectual e a incompetência prática.

Moral da história: não é à toa chegar aonde chegamos. O prolongamento histórico do capital, em suas diversas e variadas tipificações, inclusive aqueles casos impensáveis, como o chinês (será que alguém tem alguma dúvida a respeito?), isto é, o capital em sua expansão mais universalizada (intensiva e extensivamente) representa certamente a força determinante que revela a natureza da circunstância vivida hoje mundialmente. $\mathrm{O}$ surgimento e a disseminação de um vírus mortal - fato até então só cogitável em filmes de ficção científica de qualidade duvidosa - evidenciaram, em certa medida, o grau e o ritmo quase incontroláveis de destruição do meio ambiente, provocada por uma lógica econômica sem precedentes na história humana, cujos sinais já se fizeram sentir quando da constatação da existência de mudanças climáticas decorrentes dos gases do efeito estufa. Ademais, deparamo-nos com a presença assombrosa de visões e posturas extremamente retrógradas e arcaicas que rapidamente se disseminaram, ganhando novos adeptos pelo mundo afora, num movimento tão irresistível quanto a lógica econômica prevalente. É claro que estes dois fenômenos estão intrinsecamente relacionados e se reforçam mutuamente.

Ledo engano daqueles que continuam a responsabilizar a ciência pelo surgimento do vírus, ao denunciar sua criação no laboratório de algum Dr. Frankenstein. Equívoco grosseiro somente equiparável àquele que, desorientado pelo ilusionismo politicista, lamenta e chora a perda das pretensas conquistas, esvanecidas em um piscar de olhos, diante de uma suposta "onda conservadora". Ao contrário do que é propalado, "eles" estavam aí, à espreita.

Desse modo, o vírus não é a "peste", ou melhor, a peste, rigorosamente falando, não se resume ao coronavírus, mas à condição humana em que vivemos. Ironicamente, o brado audível nos meios intelectuais e culturais contra a barbárie que há séculos nos 
destroça, ao arrepio de todas as evidências no sentido contrário, vitupera contra a razão, a ciência, no melhor dos casos à razão instrumental, atribuindo a estas a responsabilidade causal pela sociabilidade vigente, quando, ao inverso, a própria razão instrumental - identificada por tais tendências, sem mais, à razão - é produto daquela. O brado é, assim, unilateral e posto de pés para cima, produzindo como efeito o oposto do pretendido, pois reforça a sociabilidade vigente, ao deixá-la intocada pela crítica. A postura irracionalista "fundamenta" e justifica o homem destroçado, o único condizente e propício, adequado na medida exata ao mundo do capital - o homem destituído de sua humanidade, estranhado em relação ao seu ser, por isso mesmo o tipo de individualidade produzida pela (des)ordem societária do capital e rigorosamente ajustada às necessidades deste. A emergência do vírus, a sua proliferação e as reações "negacionistas" só vieram colocar a nu o grande imbróglio que se tornou o mundo em que domina o "futuro ausente".

\section{Edição especial em homenagem ao cinquentenário da morte de György Lukács}

A presente edição on-line da revista Verinotio traz aos leitores um conjunto de artigos, traduções e resenhas dedicados à obra de György Lukács, que tem como objetivo, em primeiro lugar, divulgar textos fundamentais de sua autoria, até então indisponíveis (integral ou parcialmente) em português, sendo um deles, o que leva o título de "Heidegger Redivivus", publicado aqui em edição bilíngue. E, em segundo lugar, neste número especial, comparecem contribuições apuradas acerca das características fundamentais da obra filosófica do autor.

Acreditamos que a melhor maneira de homenagear um pensador como Lukács é trazer à baila os aspectos decisivos da vasta obra que nos legou, uma das mais importantes, sem dúvida, na história do marxismo, tanto no que se refere às conquistas que logrou, sobretudo no campo da filosofia em geral, e da estética em particular (a este tema específico dedicaremos nossa próxima edição), domínios esses em que preencheu espaços que o "marxismo oficial" descurou. No entanto, além disso, é imprescindível também apontar os eventuais equívocos que incorreu, assim como os problemas que deixou em aberto, não por incúria pessoal ou oportunismo, mas por limites postos pela própria época e lugar em que viveu.

Não por acaso, a primeira tradução ora publicada diz respeito à sobrevivência da ideologia fascista, depois de terminada a segunda guerra mundial, tema de extrema 
importância nos dias que se seguem. Lukács participou de um encontro internacional em Genebra, em 1946, cujo tema geral foi "O espírito europeu". Na conferência proferida por ele, já é possível encontrar de forma enfática as teses que irá desenvolver mais tarde no livro $A$ destruição da razão. O leitor atento poderá, assim, constatar a preocupação de Lukács com "as raízes espirituais do fascismo" as quais, segundo ele, podem ser identificadas sinteticamente em "quatro grandes complexos: crise da democracia, crise da ideia de progresso, crise da crença na razão e crise do humanismo" (cf. p. 10). Na dita conferência, Lukács se propõe a demonstrar como cada uma delas e, as quatro em seu conjunto, propiciaram o advento de visões de mundo regressivas que redundaram no aparecimento do fascismo.

Como tem sido prática adotada pela revista, as traduções de textos clássicos são acompanhadas por uma apresentação em que são destacadas e esclarecidas as principais questões abordadas pelos autores. Assim, no caso da conferência sobre "O espírito europeu", a apresentação foi elaborada por Carolina Peters (também responsável pela tradução) e Murilo Leite.

Em relação ao texto intitulado "Heidegger Redivivus", a presente edição traz a apresentação escrita por Vitor B. Sartori, que possui o mérito de localizar, contextualizar e esclarecer as principais características da crítica lukácsiana ao pensamento do filósofo da Floresta Negra, além é claro, de sublinhar a sua importância na atualidade. Tão importante que neste mesmo número publicamos um artigo de Ronaldo V. Fortes também voltado ao assunto, intitulado "Sobre os elementos da crítica lukácsiana a Heidegger: de $A$ destruição da razão a Para uma ontologia do ser social'.

De fato, ao longo de aproximadamente vinte anos, desde 1948 até a elaboração de sua obra postumamente publicada, o problema atinente à filosofia de Heidegger esteve presente, ainda que em Marxismo ou Existencialismo os alvos mais próximos tenham sido Sartre, Beauvoir e Merleau-Ponty. É plausível admitir, no entanto, que, na sequência dos anos, Lukács tenha se dado conta do significado pensamento heideggeriano para a filosofia contemporânea, e não apenas como autor de uma obra pré-fascista, como é considerado em $A$ destruição da razão. Tudo indica que, ao decidir entrar no campo da discussão propriamente ontológica, Lukács tenha percebido que o acerto de contas decisivo deveria se dar com Heidegger, e não tanto com Nietzsche, por mais que a obra deste último tenha apresentado afinidades decisivas com a 
ideologia nazifascista. Como bem explana Ronaldo V. Fortes em seu artigo, em Para uma ontologia do ser social é contraposta à ontologia existencialista "a ontologia do ser social desdobrada a partir da obra marxiana. A crítica a Heidegger já não figura como o cerne do problema, surge a propósito das consequências dos desdobramentos do próprio pensamento lukácsiano" (cf. p. 261).

As contribuições publicadas na presente edição da Verinotio revelam que o devido entendimento da contribuição do pensamento de Lukács passa necessariamente por aprofundamentos, discussões e críticas abalizadas acerca do pensamento filosófico contemporâneo, cuja necessária compreensão é vital para enfrentar o embate ideológico da atualidade. Não será com rótulos, palavras de ordem vazias e clichês de toda ordem que tal enfrentamento pode ser efetivado. Infelizmente, como já foi assinalado nas primeiras linhas deste editorial, esse embate já possui vencedores, tanto no século passado como hoje. O próprio fato de Lukács ter atinado para o problema apenas no final da vida, em obra inconclusa, quando tudo estava desmoronando, como denunciava Chasin em suas últimas aulas, revela o quanto estamos atrasados nesse campo. De fato, não se trata de uma discussão fácil de compreender e de levar adiante, principalmente, em um contexto em que a área de filosofia no mundo acadêmico, como já foi ressaltado, sistematicamente coíbe e restringe projetos dessa ordem. Ademais, como a obra de Lukács tem sido recebida em setores onde a formação de seus integrantes, no mais das vezes, passa ao largo de conteúdos filosóficos propriamente ditos, esse núcleo fundamental passa desapercebido ou mesmo nem é reconhecido devidamente, restando apenas apropriações de caráter sociológico de algumas categorias que, em realidade, são eminentemente filosóficas. Não há como deixar de constatar o empobrecimento que isso significa na recepção das obras do filósofo húngaro.

A presente edição da Verinotio, assim como todas as suas edições anteriores, visa contribuir para o preenchimento dessa lamentável lacuna. Nesse sentido, destacase a tradução de uma intervenção de autoria de Hans Heinz Holz, intitulada "György Lukács e o problema do irracionalismo", em que é sublinhada a importância do filósofo para a geração do autor. Num depoimento de talhe autobiográfico, Holz refere, inclusive, o impacto gerado pela leitura da intervenção de Lukács em Genebra (publicada no presente número), assim como de outros escritos, entre aqueles jovens empenhados justamente na luta ideológica após a Segunda Guerra Mundial. 
Ainda a esse respeito, como bem demonstra N. Tertulian no artigo "György Lukács e o stalinismo", a batalha ideológica encetada por Lukács também se desenvolvia em outra frente: a crítica radical do "socialismo de caserna" e o empenho em reformas que levassem à reestruturação cabal das sociedades ditas socialistas. Destaca também a relevância do Círculo Petöfi, o papel relevante que Lukács aí desempenhou, bem como o receio que iniciativas dessa ordem se proliferasse, por exemplo, na RDA. Tertulian ressalta ainda o combate travado por Lukács, sobretudo nos últimos anos de sua vida, ainda amplamente subestimado, nos seguintes termos: "Lukács estava convencido de que, longe de ser um fenômeno histórico passageiro, circunscrito à vida daquele que lhe deu o nome, o fenômeno do stalinismo, tornado forma mentis, devastaria ainda por muito tempo o movimento comunista internacional" (cf. p. 92). Enfim, criticado e censurado por todos os lados, desbravou campos de investigação até então inexplorados (com raríssimas exceções), em grande medida de forma solitária.

Um dos grandes divulgadores e intérpretes do pensamento lukácsiano no Brasil foi, sem dúvida, J. Chasin. Por isso, na presente edição, não poderíamos deixar de publicar uma de suas maiores contribuições para o estudo do autor em tela. Trata-se de uma apreciação crítica a respeito da categoria da particularidade, tal como tematizada por Lukács no livro Introdução a uma estética marxista, título recebido em sua primeira edição no Brasil em 1978. Este importante texto, intitulado "Da teoria das abstrações à crítica de Lukács" é, na verdade, um dos capítulos do livro Marx: estatuto ontológico e resolução metodológica, publicado pela Boitempo, em 2009, e que acaba de ganhar sua terceira reimpressão. Também nesse caso, publicamos uma longa e cuidadosa apresentação escrita por Vânia Noeli Ferreira de Assunção. De fato, - argumento desenvolvido por Chasin nesse capítulo em especial exigiu que tal encaminhamento fosse tomado, a fim de contextualizar e esclarecer a globalidade que a proposta chasiniana encerra. Ademais, trata-se de uma análise crítica detalhada, colada ao texto, que denuncia a presença, na avaliação lukácsiana do assunto, de um "elo lógico" entre Marx e Hegel. Entretanto, depois de um cotejamento cuidadoso da obra lukácsiana de 1956, de acordo com Chasin, "não há como ligar esses dois autores, no plano lógico, por meio de arrimos textuais diretos, não só porque estes efetivamente inexistem, mas também porque os pronunciamentos marxianos a respeito desautorizam essa velha hipótese, bem como, exponencialmente, suas declarações relativas à própria atividade científica apontam para rumos inteiramente diversos" (cf. 
p. 195).

A avaliação de Chasin a respeito dessa questão é de suma importância, na exata medida em que um dos problemas deixados em aberto pela obra de Lukács diz respeito ao lugar e à importância conferida a Hegel no trânsito e na própria emergência do pensamento marxiano.

As relações entre filosofia e sociedade são examinadas no artigo de autoria de Ester Vaisman, intitulado "O que é possível dizer sobre as relações entre filosofia e sociedade em pleno século XXI?". Nele, a autora se dedica, num primeiro momento, a denunciar como dois expoentes de tendências filosóficas predominantes, no contexto contemporâneo, abordam a questão para, em seguida, evidenciar o modo como tais relações são tematizadas por Marx e Lukács. Nesse aspecto, a autora ressalta o sentido real da noção de "determinação social do pensamento", abraçada tanto por Marx quanto por Lukács, sublinhando enfaticamente que esta nada tem a ver com postulações mecânicas entre filosofia e sociedade.

Estreitamente relacionado com o tema acima, tem-se o artigo de autoria de Vitor B. Sartori, que leva o título de "Lukács diante do Direito e da autonomização da esfera jurídica no capitalismo". Nele, o autor tem como objetivo fundamental esclarecer que a forma pela qual "Lukács trata do complexo jurídico pode ser de enorme ajuda na compreensão acerca do modo pelo qual a mediação jurídica se põe no desenvolvimento histórico e objetivo da sociedade capitalista" (cf. p. 310). Para tanto, discute-se um problema chave no tratamento do tema, e que diz respeito ao grau de autonomia que a esfera do direito desfruta, enquanto complexo específico, no conjunto da vida social. Ademais, são identificadas as funções precisas que tal esfera ideológica desempenha junto aos conflitos básicos da sociabilidade capitalista.

A contribuição de Ana Selva Albinati volta-se à discussão acerca do valor e do dever-ser na obra lukácsiana postumamente publicada, estampada no artigo "Ontologia do ser social: considerações sobre o valor e o dever-ser em Lukács". Entre outras avaliações de suma importância, a autora indica que:

Recusando as formulações filosóficas que atribuem um dever-ser aos seres naturais na forma de uma teleologia de origem transcendente, $O$ autor encaminha sua reflexão no sentido de demonstrar a gênese do dever-ser e do valor - duas categorias estreitamente relacionadas - no processo de trabalho, quando, ao lidar com a objetividade natural, o homem projeta e realiza uma objetividade para-nós, moldando o que se deseja a partir de um ser em si que porta determinadas potencialidades (cf. p. 339). 
A autora ressalta, ainda, o enfrentamento crítico de Lukács a respeito de duas tendências filosóficas, a primeira, denominada por ele de "relativismo histórico" e, a segunda de "dogmatismo lógico-sistemático" que desvirtuam a gênese real dos valores e do dever-ser ao dicotomizar os elementos imbrincados na escolha moral.

Mais um importante aporte, de cunho eminentemente filosófico, de autoria de Ronaldo V. Fortes, para a edição que abre a nova fase da revista Verinotio, se encontra no artigo "O sentido e a extensão da crítica lukácsiana à ontologia de Nicolai Hartmann". O autor aborda criticamente certas aproximações que são estabelecidas, entre as obras de G. Lukács e N. Hartmann, por dois intérpretes gabaritados de Lukács, como Nicolas Tertulian e, em menor proporção, o próprio Guido Oldrini. Fortes identifica na figura de Wolfgang Harich a fonte inicial dos comentários acerca de uma suposta influência das investigações de Hartmann sobre a obra derradeira de Lukács. Contudo, o artigo de autoria de Fortes traz à baila enorme quantidade de elementos textuais das obras dos dois filósofos (com especial atenção, evidentemente, às de Lukács), analisados com todo o rigor e vagar, que problematizam as pretensas afinidades entre ambos.

Em homenagem explícita à efeméride dos 50 anos da morte de Lukács, Maurício Vieira Martins escreve o artigo “'O senhor é um persa?' 50 anos sem G. Lukács”, título inspirado em um comentário feito para István Eörsi (em Pensamento Vivido, autobiografia sob forma de diálogo) a propósito de sua participação naquela conferência internacional de filosofia, de 1946, em Genebra, cujo conteúdo publicamos também no presente número. Ironias à parte, o autor tem como objetivo explicar as diferenças entre a proposta ontológica de Lukács e o modo como o tema foi tratado ao longo da história da filosofia.

Antônio José Lopes Alves se debruça sobre os Prolegômenos para uma ontologia do ser social buscando determinar o modo como Lukács, nessa obra em particular, caracteriza a cientificidade inaugurada por Marx. Para tanto, o autor assinala, em um primeiro momento, as diferenças de tratamento sobre o tema na Ontologia propriamente dita e nos seus Prolegômenos, para depois afirmar que, de acordo com o filósofo húngaro, o marxismo não teria conseguido identificar a questão do "centro nervoso" do pensamento de Marx "e a deixou à mercê das aproximações irracionalistas ou subjetivistas" (cf. p. 404).

Não poderia faltar, na presente edição, uma homenagem à memória do grande 
amigo Mario Duayer. E nada mais justo que essa merecida homenagem fosse realizada por um grande amigo e colaborador próximo dos trabalhos empreendidos por Duayer, principalmente nos últimos anos. Com esse propósito em mente, convidamos Paulo Henrique Furtado de Araújo que, gentilmente, aceitou prestar uma linda e comovente homenagem com o texto intitulado "Em memória de Mario Duayer".

Duas resenhas também foram publicadas. A primeira, de autoria de Ana Selva Albinati, se intitula "Por que ler hoje $A$ destruição da razão?". Nela, a resenhista, logo no início de seus comentários, refere "a ousadia" em sua recente publicação no Brasil, sobretudo tendo em vista "que tal publicação se dê em um momento ainda mais hostil à reflexão ali contida, o que só a torna mais oportuna e necessária: tempo em que o irracionalismo se espraia em suas expressões mais vulgares e de forma mais disseminada" (cf p. 452). Com efeito, a resenha reconstitui, de modo competente, os passos analíticos do autor, com a finalidade de trazer à luz os aspectos centrais dessa importante obra de Lukács para a devida identificação do cerne teórico do irracionalismo alemão, em suas distintas figuras, de modo a explicar como se veio formar o caudal ideológico que redundou no aparecimento do nazismo.

A segunda resenha é de autoria de Matheus Correa de Sousa Heleno e versa sobre o livro de Vitor B. Sartori, Ontologia nos extremos: o embate Heidegger e Lukács, uma introdução, publicado em 2019. Nesse caso também o resenhista se dedica com esmero na reconstituição dos passos do autor, que envereda por um campo de difícil investigação, pois teve em mira estabelecer as características de duas posições completamente antagônicas no cenário filosófico contemporâneo.

Para finalizar, é necessário dizer que o público leitor tem diante de si uma publicação que faz jus ao legado de György Lukács. Os textos aqui apresentados têm como características distintivas o rigor e a seriedade no trato do pensamento de um autor fundamental, cinquenta anos depois de sua morte.

Boa leitura!

Ester Vaisman

\section{Referências bibliog ráficas}

BARRADAS BARATA. Dez coisas que você deveria saber sobre o Qualis. Revista Brasileira de Pós-Graduação, v. 13, n. 30, 22 dez. 2016.

CHASIN, J. Rota e prospectiva de um projeto marxista. Ensaios Ad Hominem, v. I, t. I, São Paulo, Estudos e Edições Ad Hominem, 1999. 
GABARDO, E.; HACHEM, D. W.; HAMADA, G. Sistema qualis: análise crítica da política de avaliação de periódicos científicos no Brasil. Revista do Direito, Santa Cruz do Sul, v. 1, n. 54, p. 144-185, jan./abr. 2018.

MARQUES, F. A escala da discórdia: novos critérios do Sistema Qualis, da Capes, recebem críticas da comunidade científica. Pesquisa Fapesp, Edição 160, jun. 2009. Disponível em: <https://revistapesquisa.fapesp.br/a-escala-da-discordia/ $\geq$, acesso em 9 jul. 2021.

YAMASHITA, M. T. É hora de dissociar fator de impacto de qualidade de pesquisa. Jornal da Unesp, jul. 2021. Disponível em: <https://jornal.unesp.br/2021/07/06/ehora-de-dissociar-fator-de-impacto-de-qualidade-de-

pesquisa/?fbclid=IwAR2EiOoN9MjyQpWYGjmF7Xzh4080oAzNqYk5LrzM8lwZ9CO F7DtGsc4OJnO $\geq$, acesso em 9 jul. 2021.

\section{Como citar:}

VAISMAN, Ester. Editorial: Adeus ao Qualis, a nova fase e a peste!. Verinotio, Rio das Ostras, v. 27, n. 1, pp. I-XVII, jan./jun 2021. 